https://doi.org/10.37905/sibermas.v10i2.10212

\title{
Pemberdayaan Anak Jalanan Pada Komunitas Save Street Child (SSC) Sidoarjo Dengan Pelatihan Ketrampilan Pembuatan Kerajinan Tangan Untuk Meningkatkan Taraf Hidup
}

\author{
Indaria Tri Hariyani ${ }^{1}$, Denok Julianingsih ${ }^{2}$, Norma Diana Fitri ${ }^{3}$ \\ ${ }^{1,2,3}$ Prodi PG-PAUD, STKIP Bina Insan Mandiri Surabaya, Jl. Raya Menganti, Kramat, \\ Kec. Wiyung, Kota SBY, Jawa Timur 60228, Indonesia \\ email: indahariyani442@gmail.com , denokjulianingsih@stkipbim.ac.id, \\ normadiana79@gmail.com
}

\begin{abstract}
Abstrak
Pemberdayaan anak jalanan tidak hanya diberikan stimulant berupa uang dan makanan yang cukup, tetapi harus diberikan "kail" untuk meningkatkan keterampilannya. Salah satu bentuk keterampilan yang perlu diberikan kepada anak jalanan adalah dengan memberikan pelatihan membuat kerajinan tangan. Komunitas Anak Jalanan (SSC) Sidoarjo merupakan sekumpulan anak muda yang merekut anak jalanan untuk diajak belajar bersama guna diberikan ketrampilan guna meningkatkan perekonomiannya. Penelitian ini merupakan penelitian campuran dengan mengadopsi model Kemmis dan Mc Taggart. Subjek dalam penelitian ini adalah 30 anak di Sidoarjo. Mitra dalam pengabdian masyarakat ini adalah Komunitas Anak Jalanan (SSC) Sidoarjo. Analisis data kuantitatif deskriptif dengan menghitung gaincore. Dari hasil penelitian tersebut dapat dilakukan peningkatan taraf hidup dengan membuat produk kerajinan sebesar 80,7 dalam kategori sangat baik, menghasilkan produk dengan nilai tinggi 79,5 dalam kategori baik, sikap berani berwirausaha. 71,6 kategori baik, dan rencana. Untuk masa depan 82,9 dalam kategori sangat baik. Sedangkan peningkatan kreativitas anak pada empat kegiatan yaitu pembelajaran menggambar dan melukis meningkat sebesar 0,61 pada kategori sedang, pembelajaran membuat plastisin pada kategori tinggi meningkat sebesar 0,71, pembelajaran berbicara pada kategori sedang meningkat sebesar 0,68 , dan pembelajaran menulis dan bercerita pada kategori sedang meningkat sebesa 0,65. Sehingga dapat disimpulkan secara umum bahwa pemberdayaan dalam Komunitas Save Street Child (SSC) dapat meningkatkan Taraf Hidup Anak Jalanan.
\end{abstract}

Kata Kunci: Anak Jalanan; Komunitas Anak Jalanan; Kerajinan Tangan; Taraf hidup

\begin{abstract}
Empowerment of street children is not only given stimulants in the form of sufficient money and food, but must be given a "hook" to improve their skills. One form of skills that need to be given to street children is to provide training in making handicrafts. The Sidoarjo Street Children Community (SSC) is a group of young people who recruit street children to be invited to study together in order to be given skills to improve their economy. This research is a mixed study by adopting the model of Kemmis and Mc Taggart. The subjects in this study were 30 children in Sidoarjo. Partners in this community service are the Street Children Community (SSC) Sidoarjo. Descriptive quantitative data analysis by calculating the gaincore. From the results of these
\end{abstract}


studies, it can be done to increase the standard of living by making handicraft products amounting to 80.7 in the very good category, producing products with a high selling value of 79.5 in the good category, a courageous attitude to entrepreneurship of 71.6 good categories, and plans. for the future of 82.9 in the very good category. While the increase in children's creativity in four activities including learning to draw and paint increased by 0.61 in the moderate category, learning to make plasticine increased by 0.71 in the high category, learning to speak increased by 0.68 in the moderate category, and learning to write stories with an increase. of 0.65 in the medium category. So it can be concluded in general that empowerment in the Save Street Child Community (SSC) can improve the Living Standard of Street Children.

Keywords: Street children; Save Street Child Community; Handycrafts; Standard of living.

(C) 2021 Indaria Tri Hariyani, Denok Julianingsih, Norma Diana Fitri Under the license CC BY-SA 4.0

Correspondence author: Indaria Tri Hariyani indahariyani442@gmail.com, Surabaya, and Indonesia

\section{PENDAHULUAN}

Anak jalanan, pada hakikatnya, adalah "anak-anak", sama dengan anak-anak lainnya yang bukan anak jalanan. Untuk pemberdayaan anak jalanan tidak cukup hanya diberikan stimulus materi, tetapi yang paling penting adalah diberikan hak untuk memperoleh" akses " bagi perubahan kehidupan. Kehidupan anak jalanan dapat dirubah dan dirintis apabila mereka dapat memperoleh pendidikan ketrampilan minimal yang dapat meningkatkan "harga diri" dan "martabat" anak jalanan. Dengan adanya Komunitas Save Street Child (SSC) Sidoarjo anak jalanan akan diberi pelatihan, dengan mengikuti pelatihan keterampilan kerajinan tangan ini diharapkan dapat menggali potensi yang ada pada mereka, sehingga dapat menghasilkan pendapatan bagi anak jalanan sebagai biaya untuk pendidikannya. Selain itu, juga bisa sebagai bekal untuk bekerja di sektor industri kreatif atau dengan membuka usaha mandiri. 
Meningkatkan taraf hidup anak jalanan diperlukan ketrampilan kerajinan tangan. Kerajinan tangan adalah kegiatan seni yang mengolah bahan-bahan tertentu menjadi produk yang tidak hanya bermanfaat, tetapi juga mengandung nilai estetika (Yopi N. Nasir, 2013: 5). Kerajinan tangan biasanya mengutamakan keterampilan tangan sebagai media dalam membuat benda-benda kerajinan sehingga memiliki nilai jual yang tinggi. Kerajinan tangan bisa dilakukan dengan memanfaatkan barang-barang yang berlebihan yang kemungkinan bisa diolah menjadi barang-barang yang multi fungsi dan bernilai guna. Yopi N. Nasir (2013: 6) menyatakan bahwa produk kerajinan tangan memiliki fungsi dan peranan yang sangat beragam yaitu sebagai pendukung edukasi, sebagai dekorasi/ hiasan, sebagai benda fungsional, sebagai mainan dan sebagai souvenir/cinderamata. Dari pendapat ahli diatas dapat disimpulkan bahwa ketrampilan kerajinan tanga merupakan kegiatan seni yang mengutamakan keterampilan tangan sebagai media dalam membuat benda-benda kerajinan menjadi produk yang tidak hanya bermanfaat, tetapi juga mengandung nilai estetika.

Namun fakta di lapangan Laporan Yayasan Kesejahteraan Anak Indonesia (2004) memberikan bahwa fenomena anak jalanan semakin meningkat baik segi kualitas maupun kuantintitas. Permasalahan yang dialami anak jalan berbagai macam seperti tindak kekerasan baik fisik/psikis, ekonomi, maupun kekerasan sosial. Kebanyakan kekerasan akibat dari ketidak maupuan orang tua yang tidak dapat memenuhi kebutuhan dasar mereka, diantaranya faktor-faktor intermediasi seperti harmoni keluarga, kemampuan pengasuhan anak dan langkanya dukungan keluarga pada saat krisis keluarga dirumah. 
Berdasarkan data Hasil Survei Sosial Ekonomi Nasional (SUSENAS) Badan Pusat Statistik Republik Indonesia tahun 2008, menunjukkan bahwa anak jalanan secara nasional berjumlah sekitar 2,8 juta anak. Dua tahun kemudian, tahun 2010, angka tersebut mengalami kenaikan sekitar 5,4\%, sehingga jumlahnya menjadi 3,1 juta anak. Pada tahun yang sama, anak yang tergolong rawan menjadi anak jalanan berjumlah 10,3 juta anak atau 17,6\% dari populasi anak di Indonesia, yaitu 58,7 juta anak (Bagong Suyanto, 2011). Hidup dan berada di jalanan bukanlah tempat yang layak untuk membantu tumbuh kembang anak secara optimal karena resiko eksploitasi dan ancaman kekerasan merupakan dua hal yang terkadang sekaligus dialami dan terpaksa dirasakan oleh anak jalanan. Sehingga resiko tinggal atau hidup dijalan akan melekat pada diri anak dan anak menjadi tidak mempunyai keterampilan di sektor lain, tidak memiliki identitas diri dengan sempurna, internalisasi perilaku, traumatized dan stigamatized serta reproduksi kekerasan (Arief Armai, 2012).

Anak jalanan memiliki banyak pengalaman yang berasal dari budaya keras dan tidak semuanya diterima oleh masyarakat. Oleh karena itu, perlu ada pelatihan ketrampilan tangan pada anak jalanan dalam membantu meningkatkan taraf hidup mereka, pelatihan ini usaha agar mereka menjadi warga masyarakat yang produktif. Hal ini dapat diumpamakan dengan memberi kail kepada anak jalanan dengan harapan ketika, ikan yang dikonsumsi anak jalanan habis, anak jalan ini akan kembali berusaha mengailnya sendiri karena mereka punya cara sendiri untuk hal itu. Dengan demikian, pemberdayaan anak jalanan ini dapat menyelamatkan anak jalanan dengan mencegah berbagai 
masalah lain, baik dalam menghindari eksploitasi dalam pekerjaan maupun masalah dalam penampilan perilaku.

Komunitas Save Street Child (SSC) Sidoarjo merupakan salah satu dari sekian banyak komunitas anak jalanan yang bertujuan memberikan keterampilan kerajinan tangan pada anak jalanan untuk membuat produk dan agar meningkatkan taraf hidup serta perekonomian mereka . Lokasi Komunitas Save Street Child (SSC) berada di Jl. Entalsewu RT. 13 RW 04 Kecamatan Buduran Kabupaten Sidoarjo. Tempat ini dibangun berdasarkan gagasan dari anak muda yang bernama Dwi Prasetyo karena pemuda ini merasa prihatin dengan kondisi anak jalan itu.

Dari hasil obeservasi dan wawancara, Saat ini ada 30 anak yang mau belajar di Komunitas Save Street Child (SSC) Sidoarjo "Rata-rata mereka sekolah dan untuk biaya sekolahnya itu mereka mengamen". Komunitas ini merasa prihatin dengan kondisi anak-anak jalanan tersebut, melihat mereka berusaha untuk membiayai pendidikan sendiri dikarenakan orang tua mereka telah tiada, kesulitan keuangan keluarga atau tekanan kemiskinan, ketidakharmonisan rumah tangga orang tua, dan masalah khusus menyangkut hubungan anak dengan orang tua. Sehingga anak jalanan ini hanya mengandalkan mengamen sebagai satu-satunya usaha memperoleh biaya untuk pendidikannya. Jika hal ini dibiarkan, maka anak-anak jalanan tersebut akan menjadi manusia yang tidak berkembang dari perekonomiannya.

Komunitas Save Street Child (SSC) selama ini berusaha untuk membantu mengatasi masalah tersebut. Namun mereka juga mengalami beberapa kesulitan antara lain keterbatasan sarana prasarana, dan kekurangan sumber daya manusia dalam memberikan 
pelatihan ketrampilan yang diberikan. Anggota yang dimiliki Komunitas Save Street Child bukan pakar/ahli dibidangnya sehingga beberapa kegiatan dilakukan dengan hasil yang kurang maksimal. Selain itu kurangnya ketrampilan dan keterbatasan sarana prasarana yang dimiliki membuat beberapa program yang direncanakan oleh Komunitas Save Street Child belum terlaksana.

Berdasarkan uraian diatas maka peneliti bekerjasama dengan Komunitas Save Street Child (SSC) untuk melaksanakan pengabdian masyarakat dengan judul "Pemberdayaan Anak Jalanan Pada Komunitas Save Street Child (SSC) Sidoarjo Dengan Pelatihan Ketrampilan Pembuatan Kerajinan Tangan Untuk Meningkatkan Taraf Hidup". Tujuan penelitian ini untuk meningkatkan Taraf Hidup Anak Jalanan Pada Komunitas Save Street Child (SSC) Sidoarjo. Peningkatkan taraf hidup anak jalanan dengan cara pelatihan kerajinan tangan, pelatihan peningkatan kreativitas, serta pembentukan kesadaran jiwa kewirausahaan.

\section{METODE PELAKSANAAN}

Jenis penelitian ini merupakan penelitian kombinasi (Mixed Research) dengan mengadopsi model Kemmis dan Mc Taggart. Subjek dalam penelitian ini adalah berjumlah 30 Jalanan Pada Komunitas Save Street Child (SSC) Sidoarjo Uji lapangan ini digunakan untuk melihat peningkatan taraf hidup dengan cara peningkatan kreativitas dan pembentukan kesadaran jiwa kewirausahaan. Lokasi Mitra dalam pengabdian kepada masyarakat yaitu pada Anak Jalanan Pada Komunitas Save Street Child (SSC) 
Kabupaten Sidoarjo. Adapun tahapan dalam pelaksanaan penelitian ini dapat diamati pada Gambar 1

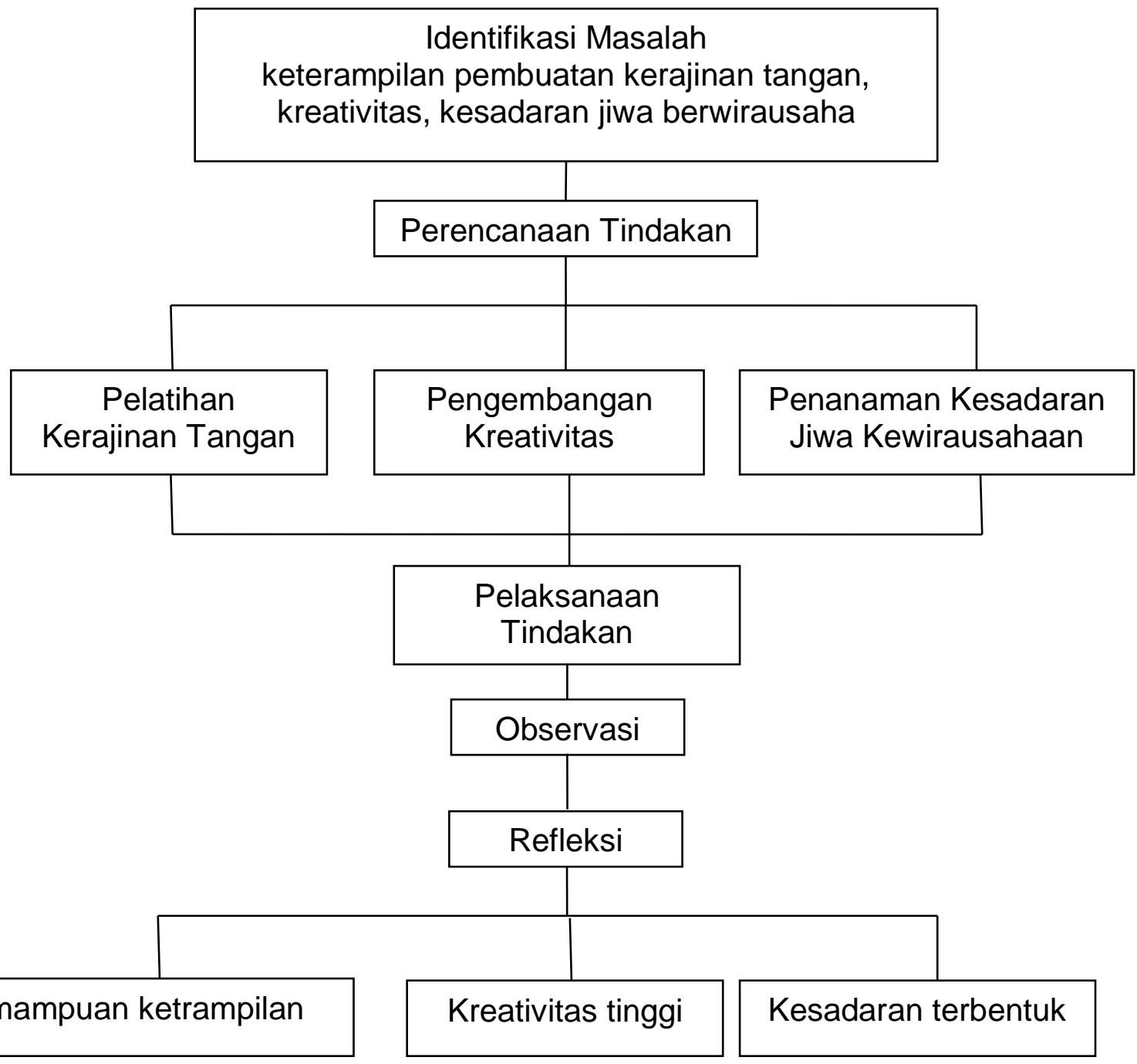

Gambar 1. Rancangan Penelitian Kombinasi (Mixed Reasearch) (diadopsi dari Model Kemmis dan Mc Taggart)

Teknik pengumpulan data yang dilakukan dalam penelitian ini meliputi observasi dan pemberian tes sesuai dengan indikator dan tujuan pembelajaran yang telah disusun oleh peneliti. Sedangkan listrumen penelitian yang akan digunakan dalam penelitian ini antara 
lain lembar observasi terhadap kreativitas dan kerajinan tangan saat pelatihan kreativitas dan pembuatan kerajinan tangan dan penanaman kesadaran jiwa kewirausahaan.

Analisis data dalam penelitian ini dilakukan secara deskriptif kualitatif- kuantitatif. Analisis deskriptif kualitatif meliputi 1) identifikasi masalah, 2) perencanan tindakan, 3) pelaksanaan tindakan. Sedangkan analisis deskriptif kuantitatif meliputi:

1) Observasi pengembangan kreativitas dan pembuatan kerajinan tangan anak menggunakan rumus:

$$
M=\frac{\sum f x}{N} \times 100
$$

Keterangan:

$M=$ mean (nilai rata-rata)

$\sum f x=$ jumlah skor yang diperoleh

$\mathrm{N}=$ jumlah skor maksimal

2) Tes

Hasil tes anak kemudian dihitung menggunakan gainscore menurut Hake (1999) dengan rumus:

$$
N G=\frac{S_{\text {post }}-S_{\text {pre }}}{S_{\text {maks }}-S_{\text {pre }}}
$$

Keterangan: NG = gainscore

$$
\begin{aligned}
& \mathrm{S}_{\text {pre }}=\text { nilai pretest } \\
& \mathrm{S}_{\text {post }}=\text { nilai posttest } \\
& \mathrm{S}_{\text {maks }}=\text { nilai maksimal }
\end{aligned}
$$


Nilai peningkatan kemampuan berhitung anak kemudian diinterpretasikan pada tabel berikut: (Hake: 2011)

Tabel 1. Interpretasi Gainscore

\begin{tabular}{ll}
\hline Gainscore & Interpretasi \\
\hline NG $>0.7$ & Tinggi \\
$0.3<$ NG $\leq 0.7$ & Sedang \\
NG $\leq 0.3$ & Rendah \\
\hline
\end{tabular}

\section{HASIL DAN PEMBAHASAN}

\section{Hasil}

Hasil observasi peningkatan taraf hidup anak jalanan pada komunitas Save Street Child diamati dalam empat kegiatan, yaitu membuat kerajinan tangan, menghasilkan produk dengan nilai jual tinggi, menumbuhkan sikap keberani untuk berwirausaha, dan membuat target dan rencana untuk masa depan. Adapun rangkuman hasil peningkatan taraf hidup dapat dilihat pada Tabel 3.

Tabel 3. Observasi Kegiatan Peningkatan Taraf Hidup Anak Jalanan Pada Komunitas Save Street Child (SSC)

\begin{tabular}{|c|c|c|c|}
\hline No & Kegiatan Yang Diamati & $\begin{array}{c}\text { Rata-Rata } \\
\text { Skor }\end{array}$ & Kriteria \\
\hline 1 & Membuat Kerajinan Tangan & 80,7 & Amat Baik \\
\hline \multirow[t]{2}{*}{2} & Menghasilkan Produk & 79,5 & Baik \\
\hline & Dengan Nilai Jual Tinggi & & \\
\hline \multirow[t]{2}{*}{3} & Menumbuhkan Sikap & 71,6 & Baik \\
\hline & Keberani Untuk & & \\
\hline
\end{tabular}




\begin{tabular}{lll}
\hline & Berwirausaha & \\
Membuat Target Dan & $82,9 \quad$ Amat Baik \\
Rencana Untuk Masa & & \\
Depan & \\
\hline
\end{tabular}

Berdasarkan Tabel 3, hasil kegiatan peningkatan taraf hidup anak jalanan pada komunitas Save Street Child (SSC) yang mendapatkan kriteria amat baik pada kegiatan membuat kerajinan tangan dan membuat target dan rencana untuk masa depan dengan rata-rata sebesar 80,68 dan 82,95. Sementara itu, yang mendapatkan kriteria baik yaitu pada kegiatan menghasilkan produk dengan nilai jual tinggi dan sikap keberani untuk berwirausaha dengan rata-rata skor sebesar 79,54 dan 71,59.

\section{Peningkatan Kreativitas Pada Anak Jalanan Pada Komunitas Save Street Child (SSC)}

Dari hasil observasi, peningkatan kreativitas pada anak jalanan pada komunitas Save Street Child (SSC) diamati dalam empat kegiatan, yaitu menggambar dan melukis membuat plastisin, berpidato, dan menulis cerita. Adapun rangkuman hasil peningkatan kreativitas dapat dilihat pada Tabel 2

Tabel 2. Hasil Belajar Jalanan Pada Komunitas Save Street Child (SSC)

\begin{tabular}{clcc}
\hline No & \multicolumn{1}{c}{ Kegiatam } & $\begin{array}{c}\text { Rata-Rata } \\
\text { Ngainscore }\end{array}$ & Kriteria \\
\hline 1 & $\begin{array}{l}\text { Belajar menggambar dan } \\
\text { melukis }\end{array}$ & 0,61 & Sedang \\
2 & Belajar membuat plastisin & 0,71 & Tinggi \\
\hline
\end{tabular}




\begin{tabular}{llll}
\hline 3 & Belajar berpidato & 0,68 & Sedang \\
4 & Belajar menulis cerita & 0,65 & Sedang \\
\hline
\end{tabular}

Berdasarkan Tabel 2, hasil peningkatan kreativitas dari kegiatan belajar menggambar dan melukis mendapatkan rata-rata Ngainscore sebesar 0,61 dengan kriteria sedang. Sementara itu, dalam belajar membuat plastisin mendapatkan rata-rata Ngainscore sebesar 0,71 dengan kriteria tinggi. Adapun yang memperoleh kriteria sedang yaitu kegiatan belajar berpidato dan belajar menulis cerita memperoleh ratarata Ngainscore sebesar 0,68 dan 0,65.

\section{Pembahasan}

Pembahsana setelah melakukan seluruh kegiatan pengabdian kepada masyarakat secara keseluruhan, ada beberapa kegiatan yang perlu diperbaiki lagi kedepannya. Saat peneliti menjelaskan beberapa materi dalam menentukan unsur cerita, beberapa anak masih belum bisa berkomunikasi dengan bahasa Indonesia yang baik dan benar. Hal ini dikarenakan, mayoritas anak memakan bahasa jawa atau bahasa daerah setempat. Selain itu, dalam hal penyampain materi kerajinan tangan beberapa anak masih belum terampil dalam pembuatan kerajinan tangan, namun ada salah satu anak yang bisa terampil dalam membuat kerajinan tangan yang bagus. Dari kegiatan menumbuhkan sikap keberani untuk berwirausaha, dan membuat target dan rencana untuk masa depan dapat tertanamnya sikap seperti pantang menyerah, ulet, jujur, inovatif, kreatif dan berani menanggung resiko. Dari hasil observasi akan diperoleh hasil tentang kemampuan membuat kerajinan tangan pada anak jalanan pada komunitas Save Street Child 
(SSC). Hasil tersebut diharapkan dapat meningkatkan taraf hidup anak jalanan pada komunitas Save Street Child (SSC) Sidoarjo.

\section{KESIMPULAN}

Berdasarkan hasil observasi dapat diambil simpulan bahwa kegiatan peningkatan taraf hidup anak jalanan pada komunitas Save Street Child (SSC) pada kegiatan membuat kerajinan tangan sebesar 80,7 dengan kategori amat baik, menghasilkan produk dengan nilai jual tinggi sebesar 79,5 pada kategori baik, sikap keberani untuk berwirausaha sebesar 71,6 pada kategori baik, dan rencana untuk masa depan sebesar 82,9 pada kategori amat baik. Sedangkan peningkatan kreativitas anak jalanan pada komunitas Save Street Child (SSC) mengalami peningkatan pada empat kegiatan yang meliputi belajar menggambar dan melukis sebesar 0,61 pada kategori sedang, belajar membuat plastisin yang meningkat sebesar 0,71 dengan kategori tinggi, belajar berpidato meningkat sebesar 0,68 dengan kategori sedang, dan belajar menulis cerita dengan peningkatan sebesar 0,65 pada kategori sedang. Sehingga dapat disimpulkan secara umum bahwa pemberdayaan Pada Komunitas Save Street Child (SSC) dapat meningkatkan Taraf Hidup Anak Jalanan.

\section{UCAPAN TERIMA KASIH}

Ucapan terimakasih disampaikan kepada semua pihak yang telah berperan dalam kegiatan pengabdian masyarakat ini, sehingga dapat dituangkan dalam bentuk tulisan artikel ini untuk dibaca seluruh pembaca. 


\section{DAFTAR PUSTAKA}

Kemis \& Mc. Taggart. (2010). The Action Research Planner. Geelong: Deaken Univercity Press

Nasir, Yopi N. (2013). Gerbang Kreativitas: Jagat Kerajinan Tangan. Jakarta: PT Bumi Aksara.

Departemen Sosial RI. (1999). Pedoman Penyelenggaraan Pembinaan Anak Jalanan Melalui Rumah Singgah. Jakarta: Departemen Sosial RI.

Suyanto, Bagong. (2011). Masalah Sosial Anak . Jakarta:Kencana Prenada Media Group.

Armai Arief . (2012) . Rumah Singgah Sebagai Tempat Alternative Pemberdayaan Anak Jalanan. Dalam Jurnal Fajar. Jakarta: LPM UIN.

Hake.R. $R$ (2011). Analyzing Change/gain scores. Unpublished. (Online), (https://www.phsics.indiana.edu/-sdi/AnalyzingChangegain.pdf. 